\title{
FIGURAÇÕES DA MORTE NA OBRA DE FRANCISCO GOITIA
}

\section{Academicismo e modernismo na América Latina ${ }^{[1]}$}

\author{
Rosângela Cherem ${ }^{[2]}$ e Kamilla Nunes ${ }^{[3]}$ \\ Participantes do Grupo de Pesquisa América Latina: Ana Lúcia Gil, Kamilla Nunes, \\ Letícia Weiduschadt e Rachel Reis de Araújo ${ }^{[4]}$ \\ Participantes do Grupo de Pesquisa Santa Catarina: Giorgio Vicenzo Filomeno e \\ Marina Rieck Borck ${ }^{[5]}$
}

\begin{abstract}
RESUMO: Dentro do arsenal imagético dos artistas latino americanos selecionados nesta pesquisa, escolhemos escrever sobre Francisco Goitia que, assombrado pelos horrores provocados pela Revolução Mexicana em toda a década de 1910, guardou numa série pictórica imagens de enforcados e cadáveres. O presente artigo é composto por três blocos que se desdobram como problemáticas relacionadas à morte enquanto dissimulação do Ser, à paisagem enquanto antemundo e à guerra como fenda que possibilita a criação artística, decorrente da consciência da completa obscuridade do homem, da arte e do cadáver.
\end{abstract}

PALAVRAS-CHAVE: Academicismo; Modernismo; Teoria e Crítica de Arte; Arte LatinoAmericana; História da Arte.

\footnotetext{
西

[

${ }^{[1]}$ Projeto Academicismo e Modernismo na América Latina.

${ }^{[2]}$ Rosângela Miranda Cherem. Professora do Departamento de Artes Plásticas do Centro de Artes, UDESC.

${ }^{[3]}$ Acadêmica do Curso de Licenciatura em Artes Plásticas. Ceart / UDESC. Bolsista PROBIC / UDESC.

${ }^{[4]}$ Acadêmicas participantes do Projeto Academicismo e Modernismo na América Latina, do mesmo grupo de pesquisa das orientadoras Rosângela Miranda Cherem (coordenadora do projeto) e Sandra Makowiecky (docente participante). Kamilla Nunes bolsista PROBIC, acadêmica do curso de Licenciatura em Artes Plásticas; Letícia Weiduschadt, bolsista PROBIC, acadêmica do curso de Licenciatura em Artes Plásticas; Ana Lúcia Gil, bolsista PROBIC, acadêmica do curso de Licenciatura em Artes Plásticas e Raquel Reis de Araújo, bolsista voluntária, acadêmica do curso de Licenciatura em Artes Plásticas.

${ }^{[5]}$ Acadêmicos do Curso de Bacharelado em Artes Plásticas - participante da pesquisa Academicismo e Modernismo em Santa Catarina, Giorgio Vicenzo Filomeno, Ceart/UDESC, bolsista PROBIC, UDESC, Marina Rieck Borck, acadêmica do Curso de Bacharelado em Artes Plásticas - Ceart/UDESC, bolsista PROBIC, UDESC.
} 
I - Numa tentativa de intensificar o sofrimento, a dor, a barbárie e os horrores massificados causados pela guerra, num tempo em que a televisão não a tornava um espetáculo, como aconteceu em 1990 na Guerra do Golfo, com a invasão do Kuwait pelas tropas iraquianas, Francisco Goitia (1882-1980) pintou duas telas de cadáveres enforcados em árvores, já em

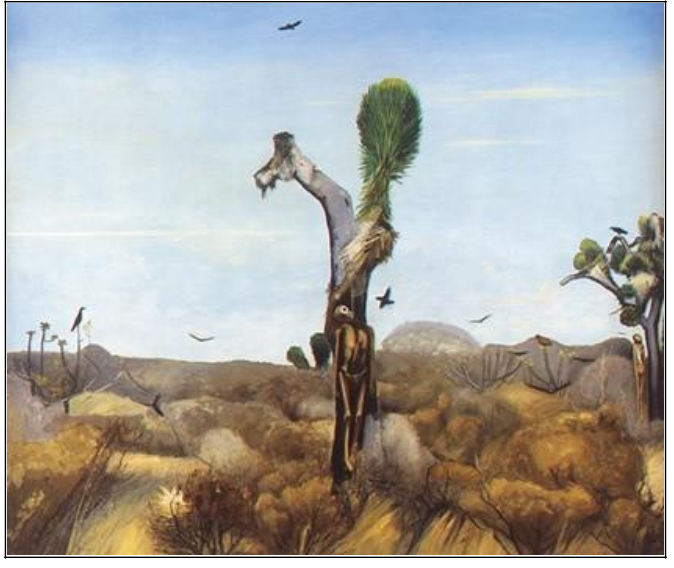

FIGURA 1 fase decomposição. Uma delas, intitulada Paisagem de Zacatecas com enforcados II, feita em 1914, ano que a revolução estava acabando, com cerca de um milhão de mexicanos mortos, o que significa $10 \%$ da população total daquela época, apresenta dois corpos suspensos em árvores, um em primeiro, outro em segundo plano, quase suprimido pelas bordas da tela. Essa duplicação de enforcados engolidos pela paisagem, com a pele junto ao osso, cuja cor é a mesma da vegetação seca e informe, remete à

aparição daquilo que deixou de ser e no entanto ainda é enquanto dissimulação. Ou seja, "quando tudo desapareceu ainda existe alguma coisa, quando tudo falta a falta faz aparecer a essência do ser que é de ser ainda onde falta” (BLANCHOT, 2001, p. 255).

As biografias do artista registram que ele pendurava os cadáveres nas árvores pelo pescoço, simulando um suicídio por enforcamento, para observar os estágios de decomposição do corpo. Este ato pode ser considerado uma tentativa obscena (aquilo que está fora de cena) de exagerar as perturbações causadas pela guerra, com o intuito de causar impacto e/ou repulsa na sociedade que viria a olhar a imagem como se esta fosse uma representação dos desastres da guerra. Tal falta de correspondência do artista com a verdade torna ainda maior o silêncio enigmático da obra de arte, que para Maurice Blanchot (1907 2003) é um não se dar a conhecer pela impossibilidade do acontecimento, ou seja, da penetração no objeto artístico. Quando nos damos conta de que a verdade dessas pinturas não é exterior a elas, compreendemos que as verdades não passam de ilusões, elas podem se tornar tão reais quanto é para o protagonista do romance a Invenção de $\mathrm{Morel}^{l}$, sua amada Faustine, ou para Marco Pólo, em As Cidades Invisíveis, os lugares que descreve para o Grande Khan².

Eis, portanto, a associação paradigmática entre o cadáver e a obra de arte. Ambos, em suas particularidades, provocam sensações semelhantes à que experimentou Jacques Derrida (1930 -) em seu banheiro sendo olhado nu por um gato, se vendo visto nu, impotente diante 
da situação lúdica criada por ele, a ponto de sentir vergonha do animal, que não reagia a seus movimentos, mas o observava com constância na fixidez de um olhar impenetrável. Enquanto

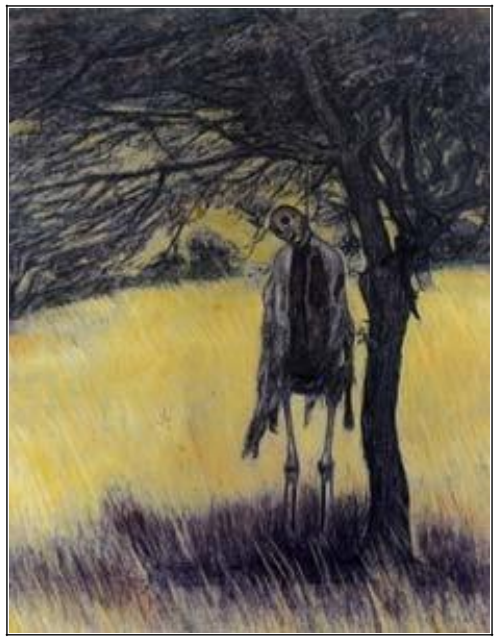

FIGURA 2 o filósofo encontra no animal, que é para ele o completamente outro, a semelhança consigo mesmo, percebendo "o limite abissal do humano: o inumano ou o a-humano, os fins do homem, ou seja, a passagem das fronteiras a partir da qual o homem ousa anunciar a si mesmo" (DERRIDA, 2002, p. 31), o artista, percebendo o inorgânico, o inestético e o informe de um corpo em decomposição, ainda que reconhecível enquanto corpo-humano, atenta para a completa obscuridade, o vazio e o silêncio que não só sucede como faz parte do humano.

Na segunda pintura que Goitia realizou durante a revolução, agora com giz pastel e intitulada $O$ enforcado, o artista mostra descobertos os ossos do corpo, revelando um

estágio avançado de decomposição. Ainda que o primeiro e segundo plano da composição possam ser distinguidos, ambos sofrem de uma interdependência rítmica, de forma que o isolamento da figura em primeiro plano implica na sua própria desfiguração. Ao contrário, por exemplo, de Francis Bacon (1909 - 1992), que costumava isolar suas figuras para "romper com a representação, interromper a narração, impedir a ilustração, liberar a figura: para ater-se ao fato" (DELEUZE, 2007, p. 12). Duas maneiras opostas de operar para chegar ao mesmo resultado: ater-se ao fato. Ao tornar o fundo tão importante quanto a figura, projeta-se uma suspensão temporal e espacial que remete ao antemundo, àquilo que não

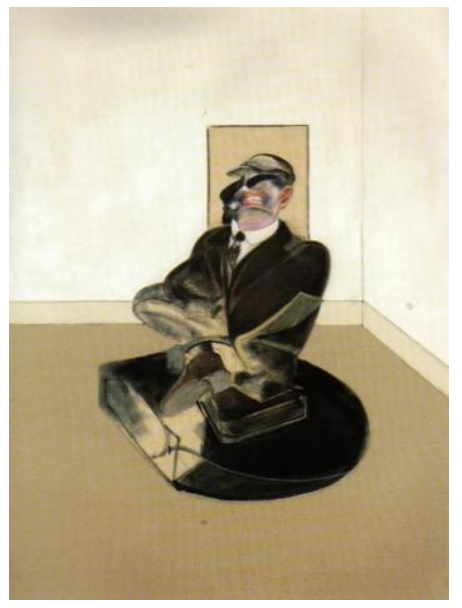

FIGURA 3 pertence mais ao mundo, "embora esteja aqui, melhor dizendo, atrás do mundo" (BLANCHOT, 2001, p. 258). O cadáver e a paisagem se dissolvem no sombrio dos tons dourados e ocres, na euforia das pinceladas verticais, que tornam análogos os planos, fazendo da paisagem um espaço que denota o Aqui Jaz, pressuposto de um sepultamento.

Essa paisagem que acolhe o cadáver é também a paisagem dos campos de batalha, manchados de sangue e providos de armadilhas para provocar a morte do inimigo, como as minas enterradas aos milhares a espera de um desavisado. Logo, o cadáver que se tornou vítima da paisagem, nas pinturas de Goitia, nela repousa até seu total desaparecimento. Sabendo que seria impossível transmitir, comunicar ou mesmo fazer o outro sentir 
parcialmente a experiência de estar na guerra, com ameaças constantes de morte, mutilações e o que resta de esperança em meio a tanta brutalidade, Goitia ultrapassou os limites da mera representação e/ou registro da guerra, assumindo a liberdade pictórica própria de uma artista que conhece as fronteiras abissais entre arte e realidade, entre sentir e expressar, entre falar e ouvir.

II - Após estudar em Barcelona com o mesmo professor de Juan Miró, Francisco Gali, e na Itália, reproduzindo em pintura as arquiteturas clássicas, Goitia regressou ao México e pouco depois serviu ao General Felipe Ángeles na Revolução Mexicana, citada no início do artigo. Anos depois, recordando a experiência, relatou: "Fui a todas as partes com seu

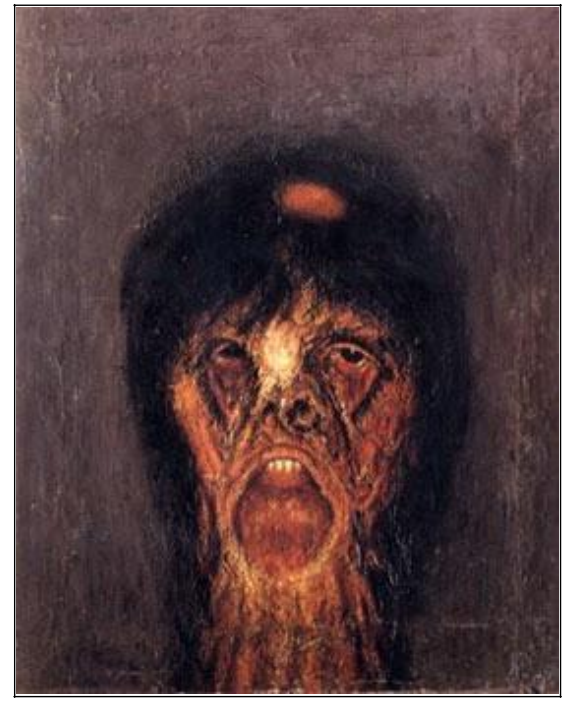

FIGURA 4 exército, observando. Nunca portei armas porque sabia que minha missão não era matar" ${ }^{3}$. Sabemos, portanto, que a única munição de que dispunha era lápis, giz pastel, tintas, folhas e telas. Percorrendo o tema do cadáver em decomposição, e não propriamente as ações de guerra, o combate em si, ele pintou a tela intitulada pelo Museo Francisco Goitia, A Bruxa, único retrato desse período. De acordo com o diretor desse museu, apenas à Tata Jesuscristo ele deu nome, todas as outras obras foram intituladas posteriormente para fins de organização do acervo e estratégia de discernimento.

A Bruxa, pintada em 1916, reflete não apenas a completa obscuridade de daquilo que se tornou o outro de si mesmo, mas também o instante inapreensível do dar-se conta da morte. Sua cabeça se liquefaz, desfaz, escapa de si mesma, transformando-se numa máscara que encobre a face da morte. Máscara não enquanto Imago, que se dá pela semelhança com o morto, portanto com o outro daquilo que já não é, mas que ainda guarda pela forma particularidades que fazem remanescer suas características físicas, mas enquanto um objeto que o oculta pela expressividade (aquilo que significa e é significada) exterior àquele do qual faz parte, ou seja, a máscara faz reviver o humano naquilo que deixou de ter a consciência de si. Percebemos então que A Bruxa suscita problemáticas referentes ao que faz de um serhumano um humano, posto que como Ser se compreende todas as coisas que são. Assim, se um cadáver é, se ele existe, ele é Ser. Mas, o que está implicado quando dizemos que ele não é mais um humano? Pergunta que permeou o pensamento de grandes filósofos como

\footnotetext{
${ }^{3}$ Citação retirada da biografia de Francisco Goitia cedida pelo Museo Francisco Goitia.
} 
Aristóteles e Heiddeger, que gerou e ainda gera debates na área da ciência com relação à eutanásia, a experimentos com células tronco, entre outros e que Goitia não se atreveu a responder, mas não cessou de se indagar.

Sabemos que A Bruxa é uma imagem advinda do olhar do pintor para um cadáver em decomposição, mas ela também remete ao informe dos corpos que sobreviveram à guerra. Pessoas cuja carne foi estraçalhada por granadas, balas, e tantas outras armas fatais. Cujo rosto se tornou irreconhecível e o corpo, pelas mutilações, não mais assumiu as funções a que era qualificado. A imagem da guerra é, então, também a imagem do disforme, da mutilação e auto-mutilação, da morte entrelaçada ao erotismo que aparece em Georges Bataille (1897 1962). Em busca do limite da literatura, num tempo do absurdo e sem esperança de futuro, da falta de coerência da realidade passada com a vida cotidiana, ele escreve o texto História do Olho, publicado originalmente em 1928. Para expressar seu desejo de apagamento, Bataille utiliza o pseudônimo de Lord Auch, que serve como máscara por trás da qual o autor pode revelar seus traumas no que diz respeito à relação com seu pai. No decorrer do romance percebemos que os personagens se arrostam com a morte de maneiras diferentes, ora com pesar, ora com perversidade, como quando, depois da atordoada morte de Marcela, Lord Aush diz:

Marcela pertencia-nos a tal ponto, em nosso isolamento, que não a víamos como uma morta qualquer. Os impulsos antagônicos que se apossaram de nós naquele dia se neutralizavam, deixando-nos cegos. Afastavam-nos para longe, para um mundo em que os gestos não têm alcance, como vozes num espaço que não é sonoro. (BATAILLE, 2003, p. 60)

Nessa perspectiva, captar o instante único e permanente daquilo que não foi, nem

FIGURA 5

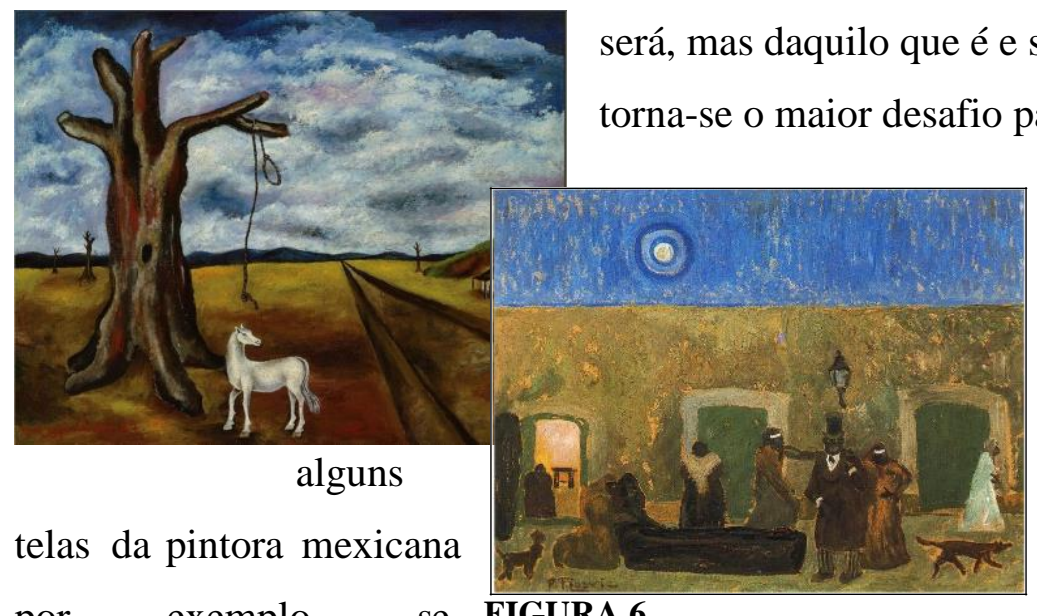

por exemplo, se FIGURA 6

sombrios e objetos que pensar a morte, a guerra, o informe e todas essas abordagens que se fazem presentes também na obra de pintores latino-americanos. As María Izquierdo (1902 - 1955), caracterizam pelos tons referenciam a morte e/ou o morto 
que, sempre na presença de cavalos, ou uma corda pende de uma árvore seca num lugar deserto, ou um caixão aparece ocultando o cadáver. Onde Goitia evidencia o corpo em decomposição, Izquierdo o solapa. Nas cenas de enterros e enfermos, a morte está nas relações taciturnas entre o cadáver oculto pelo caixão que o envolve e as pessoas que o acompanham para a última despedida. Pedro Figari (1861 - 1938), no Uruguai do início do século XX, com uma produção de caráter dramático, pintou uma série de velórios, que assim como os de Izquierdo estão imersos num ambiente melancólico, por assim dizer, lúgubre, evidenciado pelas cores terrosas, sombras indefinidas, postura dos personagens e, em alguns momentos, elementos sombrios como a lua cheia. Não obstante, em Juan Manuel Blanes (1830 - 1901), mais impactante que uma mulher esparramada no chão, vítima da febre amarela, é notar as mãos inocentes de um bebê que agarra seu vestido, no local que cobre os seios, a espera de uma resposta aos seus atos.

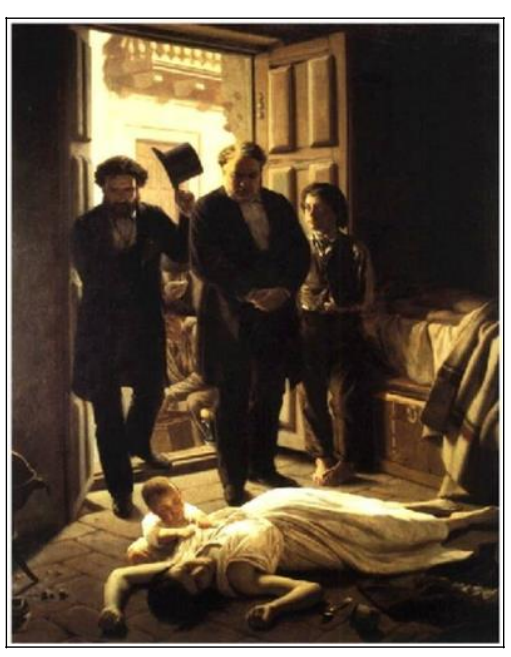

FIGURA 7

Essas diversidades de experimentos artísticos provenientes de sensibilidades e experiências intrínsecas, tanto nas artes plásticas quanto na literatura, cinema, música e teatro, abrem leques para reflexões acerca dos problemas culturais, sociais e também políticos, no âmbito da descrença e falta de esperança de um presente capaz de superar as barbáries do passado e consequentemente, de um futuro promissor, sem marcas de sangue e memórias acinzentadas. É assim o ambiente criado por Samuel Beckett (1906 - 1989),

em Fim de Partida e Esperando

\section{Godot: $\quad$ acinzentado. Seus}

personagens, concebidos na época turbulenta da pós-segunda guerra mundial tentam, através dos diálogos e da inércia a que se dispõe dar sentido a um mundo desprovido de sentido. Em Fim de Partida, os pais de HAMM, com as pernas amputadas, moram dentro de latões de lixo, enquanto HAMM, cego e impossibilitado de mover as penas, ocupa numa cadeira de rodas exatamente o centro da sala (BECKETT, 2002). Podemos perceber, portanto, a forte influência do surrealismo no teatro de Beckett e como o diretor enfatiza, com elementos cênicos pós-dramáticos, os restos humanos e a ruína.

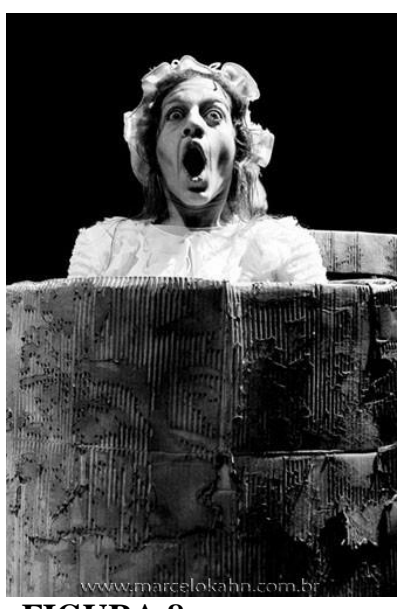

FIGURA 8 
III - Em A Idade Viril, obra autobiográfica que não obedece a uma ordem meramente cronológica dos fatos, Michel Leiris (1901 - 1990) descreve suas impressões diante dos acontecimentos das atividades cotidianas, como ir ao teatro. Ainda que o autor tenha escrito esse livro depois de romper com os surrealistas, ele continua exprimindo através da literatura, seu descontentamento com relação à guerra, como quando relata que foi tomado por um acesso de pânico depois de assistir à peça Volta ao Mundo em 80 dias, por achar que o barco ia afundar e estourar com o vapor. Ao sair do teatro, começou a berrar: "Não quero que estoure... Não quero que estoure..." Depois do ocorrido, ele enuncia relacionando os fatos: “Ainda hoje sou tentado a lançar semelhantes gritos para tentar deter a marcha dos elementos:

'Não quero que haja guerra!' eu diria, mas os elementos, como outrora, não parecem dispostos a me obedecer" (LEIRIS, 2003, p. 45). Temos aqui a impotência do homem diante da tentativa de realizar seus desejos e os meios que ele utiliza para mostrar seu descontentamento. Como reagir à beleza convulsiva, repulsiva e ao mesmo tempo atraente da guerra? Para Leiris, bem como para Goitia, a reação está diretamente vinculada à criação a partir de metáforas, dissimulações e jogos de tangência entre a ilusão da verdade e da mentira.

Foi assim que depois de aproximadamente três décadas passadas do fim da Revolução Mexicana, Francisco Goitia continuou pintando enforcados como fazia quando serviu ao

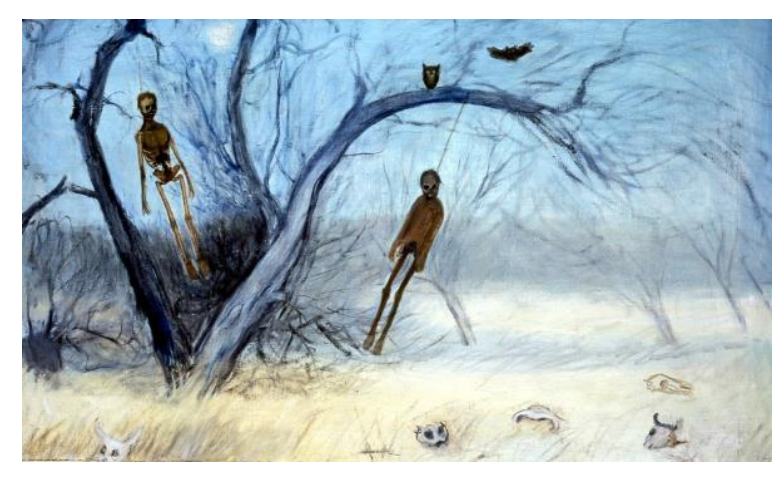

FIGURA 9 general Felipe Ángeles. As duas telas posteriores à guerra contêm nuances de azul, como se fossem imagens retidas na memória, tal qual acontece nos filmes quando as lembranças dos personagens aparecem em preto e branco. A obra Paisagem de Zacatecas com enforcados II, realizada entre $1938 \mathrm{e}$ 1942, apresenta semelhança e principalmente diferenças

marcantes com a que Goitia pintou no ano de 1914, mostrada no início desse artigo. Ambas exibem dois enforcados na árvore em meio à paisagem. Mas enquanto a primeira denota seriedade, a segunda remete ao lúdico que se manifesta nos esqueletos caricaturais de animais espalhados, a priori, aleatórios na paisagem. Os cadáveres pendurados, já decompostos, parecem volúveis e leves, como folhas secas que pendem inclinadas nas árvores,

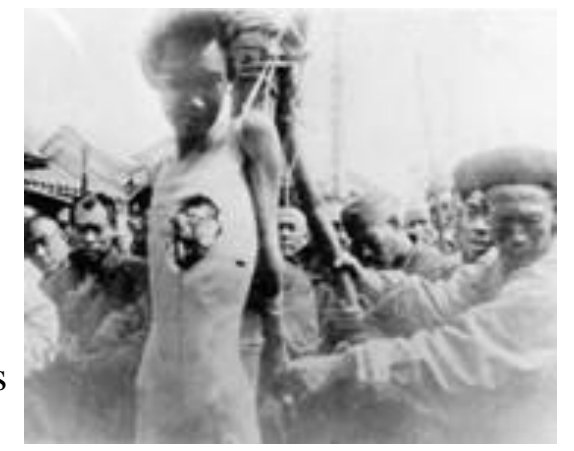

FIGURA 10 
prestes a serem carregadas por uma corrente de ar. Assim como María Izquierdo e Pedro Figari, Goitia acrescenta à cena símbolos mórbidos que aludem à morte, como a coruja e o morcego. Se olharmos atentamente, percebemos também que toda a composição está em diagonal, ora curvada para esquerda, ora para a direita, de forma que nem mesmo as cordas que suspendem os cadáveres se encontram na vertical.

Relativamente a essa instabilidade pictórica advinda de infortúnios causados por projeções imaginárias, Augusto Contador Borges (1954 -) escreve um artigo sobre o Supliciado Chinês aos olhos de Georges Bataille. No decorrer do texto o autor descreve como as imagens do supliciado afetaram e causaram vertigem em Bataille, para então entrar na discrepância entre os pontos de vista do carrasco e da vítima, até concluir que "o que temos em comum - com o carrasco - é a conseqüência das possibilidades do horror, em que cruzamentos súbitos, arrepios momentâneos, que vez por outra nos atingem no extremo de nós mesmos com a descarga elétrica de uma idéia absurda" (BORGES, 2001). Isso nos leva a pensar até que ponto os cadáveres que Goitia enforcou nas árvores para observar sua

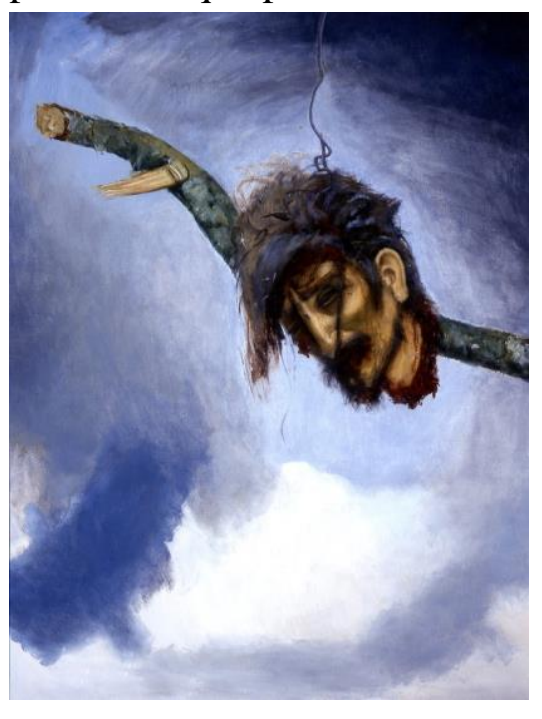
decomposição foram vítimas da guerra. Fou Li recusa a dor que o dilacera, ele a nega como Goitia negou a dor de matar o outro. Não se trata, é claro, da mesma sensação de dor, mas da mesma negação a ela. Na guerra os papéis de carrasco e vítima se alternam constantemente, ou seja, se o inimigo atira, é preciso deixar a piedade de lado e revidar o ataque, pois essa é a única maneira de escapar da morte.

Em 1958-60 Goitia pintou a tela chamada Cabeça de enforcado. Assim como Théodore Gericault (1791 - 1824), cujas naturezas-mortas compostas por cabeças decepadas

referenciam os desastres em tempos de sombra, após a FIGURA 11 queda do Império de Napoleão em 1815, Goitia acrescentou a essa pintura um caráter trágico e catastrófico outrora inexistente. Não temos mais a imagem do horror diante da morte, como na Bruxa, mas do horror diante da crueldade do homem. Enquanto José Maria Velasco, professor de Goitia no México, olhava para a FIGURA 12 ausência do homem na paisagem, Goitia olhava para a ausência do humano no homem. Sigmund Freud (1856 - 1939) em O Mal-Estar na 
Civilização fala da relação entre o instinto de vida e o instinto de destruição relacionado à disputa entre Eros e a Morte. Para Freud, a agressividade é um instinto do homem que se opõe ao programa de civilização e é também "derivado e o principal representante do instinto de morte, que descobrimos lado a lado de Eros e que com este divide o domínio do mundo." (FREUD, 1997, p. 81).

Desde criança somos condicionados a regras sociais e aprendemos a diferenciar o bem do mal, mas para Bataille "ser carrasco ou vítima nos coloca acima de nossos limites" (BATAILLE apud BORGES, 2001), de forma que é preciso que tenhamos a consciência da violência e abjeção que existe em nós. Antes da religião se perpetuar pelo mundo pregando o bem e condenando o mal, os contos mitológicos tratavam com naturalidade o instinto de agressão definido por Freud. Como exemplo, podemos citar Mercúrio, que com um só golpe decepou Argos, enviado por Juno para vigiar Io; Perseu, assim como Mercúrio, cortou a cabeça da Medusa e a entregou à Minerva, que por sua vez fixou-a no meio de sua égide, transformando o escudo numa arma mortal que petrificava todos que o olhassem; Juno enviou uma praga à civilização governada por Éaco que devastou a terra e matou todos os seus habitantes, só porque a ilha tinha o nome de uma das amantes de seu marido. Da naturalidade à barbárie, do orgulho de lutar por uma causa à injustiça advinda dela, do carrasco à vítima instâncias da diversidade de olhares e comportamentos dos que viveram as experiências da guerra e dos comprometidos a transmiti-la através da arte. A guerra é para esses artistas um lapso que permite criar, gritar, explorar sensações e um motivo a mais para manipular o caos, dando a ele forma, cor e vida. Mesmo que a forma seja informe, as cores sejam tristes e a vida vista através do cadáver. 


\section{REFERÊNCIA BIBLIOGRÁFICA}

1 BATAILLE, Georges. História do Olho. São Paulo: Cosac Naify, 2003.

2 BECKETT, Samuel. Fim de Partida. São Paulo: Cosac Naify, 2002.

3 BIOY CASARES, Adolfo. A invenção de Morel. 3. ed. - São Paulo: Cosac Naify, 2006.

4 BLANCHOT, Maurice. O espaço literário. Rio de Janeiro: Rocco, 2001.

5 BORGES, Augusto Contador. Georges Bataille: Imagens do Êxtase, 2001. Disponível em: <http://www.revista.agulha.nom.br/ag9bataille.htm> Acesso em 27 jan. 2007.

6 CALVINO, Ítalo. As cidades invisíveis. 2. ed. - São Paulo: Companhia da Letras, 2006.

7 DELEUZE, Gilles. Francis Bacon: lógica da sensação. Rio de Janeiro: Jorge Zahar Ed., 2007.

8 DERRIDA, Jacques. O animal que logo sou. São Paulo: Editora UNESP, 2002.

9 FREUD, Sigmund. O Mal-Estar na Civilização. Rio de Janeiro: Imago Ed., 1997.

10 LEIRIS, Michel. A idade viril. São Paulo: Cosac Naify, 2003.

\section{REFERÊNCIA DAS FIGURAS}

1 Francisco Goitia. Paisagem de Zacatecas com enforcados II. 1914. Óleo sobre tela, 95 x 100 $\mathrm{cm}$. Imagem cedida gentilmente pelo Museo Francisco Goitia.

2 Francisco Goitia. O enforcado. 1912 - 17. Pastel sobre papel. 53 x $42 \mathrm{~cm}$. CONACULTA INBA / Museo Francisco Goitia. Imagem cedida gentilmente pelo Museo Francisco Goitia.

3 Francis Bacon. Figura Sentada. 1979. Disponível em: 〈http://www.ciudadpintura.com>. Acesso em: 10. jun. 2008.

4 Francisco Goitia. A Bruxa. 1916. Óleo sobre tela; 30 x 33 cm. Imagem cedida gentilmente pelo Museo Francisco Goitia.

5 María Izquierdo. A corda. 1947. Óleo s/ tela. 43 x 51 cm. Disponível em:

$\leq$ http://www.museoblaisten.com/spanish.asp?myURL=\%2F02asp\%2Fspanish\%2FpaintingSp anish\%2Easp\&myVars=numID\%3D655>. Acesso em: 10. jun. 2008. 
6 Pedro Figari. Qui se charge du mort? Óleo s/ cartão. 62 x 80 cm. Coleção Museu Municipal Juan Manuel Blanes. Montevideo, Uruguay. Disponível em $<$ http://pintura.aut.org/BU04?Autnum=14155\&Empnum=0\&Inicio=76>. Acesso em: 10. jun. 2008.

7 Juan Manuel Blanes. Um episódio da febre amarela em Buenos Aires. 1871. Óleo s/ tela. 230 x 180 cm. Coleção Museu Nacional de Artes Visuais. Montevidéu, Uruguay. Disponível em: <http://revistapersona.8m.com/34DHowlin.htm>. Acesso em: 10. jun. 2008.

8 Perla Frenda em "Fim de Partida" de Samuel Beckett. Foto: Marcelo Kahn. Disponível em: <http://digitandoteatro.blogspot.com/2008/02/de-dentro-do-lato-de-lixo.html>. Acesso em: 10. jun. 2008.

9 Francisco Goitia. Paisagem de Zacatecas com enforcados II. 1938- 1942. Óleo sobre tela. 58 x 96 cm. Colección: CONACULTA - INBA / Museo Francisco Goitia. Imagen cedida gentilmente pelo Museo Francisco Goitia.

10 Fou Li. O supliciado Chinês. Disponível em:

<http://www.revista.agulha.nom.br/ag9bataille.htm> Acesso em: 10. jun. 2008.

11 Francisco Goitia. Cabeça de enforcado. 1958-60. Óleo sobre tela. 122 x 93 cm. CONACULTA - INBA / Museo Francisco Gotilla. Imagen cedida gentilmente pelo Museo Francisco Goitia.

12 Théodore Gericault. Cabeças Cortadas. 1818-1819. Óleo sobre tela, 50 x 61 cm. Coleção National Museum, Estocolmo. Disponível em: http://www1.uol.com.br/bienal/24bienal/edu/theodore_gericault_g1.htm. Acesso em: 10. jun. 2008 . 